\title{
Dietary flavonoid tangeretin induces reprogramming of epithelial to mesenchymal transition in prostate cancer cells by targeting the PI3K/Akt/mTOR signaling pathway
}

\author{
WEN-BIN ZHU ${ }^{1}$, NING XIAO ${ }^{1}$ and XING-JIE LIU ${ }^{2}$ \\ Departments of ${ }^{1}$ Urology and ${ }^{2}$ Obstetrics and Gynecology, Linyi People's Hospital, Linyi, Shandong 276003, P.R. China
}

Received October 23, 2015; Accepted June 9, 2017

DOI: $10.3892 / \mathrm{ol} .2017 .7307$

\begin{abstract}
Tangeretin, a natural polymethoxyflavone present in the peel of citrus fruits is known to exhibit anticancer properties against a variety of carcinomas. Previous experimental evidence suggests that lifestyle and dietary habits affect the risk of prostate cancer to a certain extent. As the effect of tangeretin on prostate cancer is unexplored, the present study investigated the effect of tangeretin on androgen-insensitive PC-3 cells and androgen-sensitive LNCaP cells. Tangeretin reduced the cell viability of $\mathrm{PC}-3$ cells in a dose- and time-dependent manner, with the half-maximal inhibitory concentration $\left(\mathrm{IC}_{50}\right)$ observed at $75 \mu \mathrm{M}$ dose following $72 \mathrm{~h}$ of incubation, while in $\mathrm{LNCaP}$ cells, the $\mathrm{IC}_{50}$ was identified to be $\sim 65 \mu \mathrm{M}$. Expression levels of the mesenchymal proteins including vimentin, cluster of differentiation 44 and Neural cadherin in PC-3 cells were reduced by tangeretin treatment, whereas those of the epithelial proteins, including Epithelial cadherin and cytokeratin-19 were upregulated. Treatment of PC-3 cells also resulted in the downregulation of the phosphoinositide 3-kinase/protein kinase B/mammalian target of rapamycin (PI3K/Akt/mTOR) signaling pathway. Therefore, it may be concluded that tangeretin induces reprogramming of epithelial-mesenchymal transition in PC-3 cells by targeting the $\mathrm{PI} 3 \mathrm{~K} / \mathrm{Akt} / \mathrm{mTOR}$ signaling pathway.
\end{abstract}

\section{Introduction}

Prostate cancer is the second most prevalent cancer in the United States of America, and also the second leading cause of mortality in the western world (1). Approximately $25 \%$ of all diagnoses of cancer in the male population of the United States of America are prostate cancer (2). Due to the increasing risk of prostate cancer over the previous decade, studies

Correspondence to: Mr. Xing-Jie Liu, Department of Obstetrics and Gynecology, Linyi People's Hospital, 27 East Jiefang Road, Lanshan, Linyi, Shandong 276003, P.R. China

E-mail: liuxingjiexj@hotmail.com

Key words: tangeretin, apoptosis, prostate cancer, epithelial to mesenchymal transition, protein kinase B associating lifestyle with prostate cancer risk have become increasingly prevalent (1). However, the primary etiology of prostate cancer remains obscure, as no specific carcinogen is known to be responsible for this disease (2-4). Epidemiological studies suggest that certain risk factors, including aging, Afro-American ethnicity and positive family history are associated with the likelihood of developing prostate cancer (5). However, according to several studies, genetic factors are not the sole etiology of prostate cancer; it is also associated with lifestyle, dietary and environmental factors (5-7).

The majority of prostate cancer-associated mortalities are due to the acquisition of the metastatic phenotype of the disease, and the epithelial to mesenchymal transition (EMT) is known to serve a pivotal role in tumor metastasis (8). EMT is a series of coordinated events, during which cancer cells acquire enhanced migratory and invasive properties, may invade through the basement membrane and survive in systemic circulation due to the resistance to apoptosis (8-10). This EMT is accompanied by the extravasation at distant organ sites, followed by the adhesion of cancer cells to extracellular matrix proteins, including fibronectin, which finally leads to tumor metastasis $(11,12)$. Downregulation of the gap junction protein Epithelial (E)-cadherin, which serves an important role in cell-to-cell adhesion, and the upregulation of the mesenchymal proteins Neural (N)-cadherin, vimentin, Twist-related protein 1 are known to be the hallmark events in the prostate cancer-associated EMT process $(8,10,13)$. Previous studies suggested that EMT serves a crucial role in the development and maintenance of stemness in prostate carcinoma (14-16), and is also responsible for the resistance to therapeutic drugs (17).

Flavonoids are naturally occurring polyphenols, which constitute a major part of the human diet, and are abundantly present in fruits, grains, vegetables and traditional medicinal herbs $(18,19)$. Almost all of the chemically synthesized drugs currently used in cancer therapy exhibit high toxicity to normal cells (20), but the naturally occurring flavonoids have demonstrated selective cytotoxicity to human cancer cells, with minimum toxicity to the normal cells (19). In an attempt to identify improved chemopreventive or chemotherapeutic agents, tangeretin, a 4',5,6,7,8-pentamethoxyflavone (Fig. 1A) that is abundant in the peel of citrus fruits (21), was selected. The tumor suppressive role of tangeretin is well documented, and it has been suggested to inhibit the growth and 
progression of several types of cancer cells such as ovarian cancer, colorectal, gastric and breast cancer (21-25). However; there are no studies investigating tangeretin in prostate cancer, to the best of our knowledge. Taking into consideration the potent anticancer property of tangeretin, the present study investigated the effect of this dietary flavonoid on prostate cancer PC-3 cells.

\section{Materials and methods}

Materials. Tangeretin was purchased from Sigma-Aldrich (Merck KGaA, Darmstadt, Germany). Dulbecco's modified Eagle's medium (DMEM; supplemented with $1 \mathrm{mM}$ L-glutamine), fetal bovine serum, penicillin-streptomycin and $0.25 \%$ Trypsin-EDTA were purchased from Invitrogen (Thermo Fisher Scientific, Inc., Waltham, MA, USA). Primary antibodies including rabbit polyclonal anti-B-cell lymphoma 2 (Bcl-2)-associated X protein (Bax) antibody (cat. no., sc-493), and mouse monoclonal anti- Bcl-2 antibody (cat. no., sc-7382), were purchased from Santa Cruz Biotechnology, Inc. (Dallas, TX, USA), and rabbit polyclonal anti-cleaved caspase-3 (cat. no., 9661), rabbit monoclonal cleaved anti-caspase-9 (cat. no., 7237), rabbit monoclonal anti-phosphorylated (p)-protein kinase B (pAkt; cat. no., 4060), rabbit monoclonal anti-Akt (cat. no., 4691), rabbit monoclonal anti-p-mammalian target of rapamycin (pmTOR; cat. no., 5536) and rabbit monoclonal anti-mTOR (cat. no., 2983) were purchased from Cell Signaling Technology, Inc. (Danvers, MA, USA). The single-stranded DNA (ssDNA) Apoptosis ELISA Kit (cat. no., APT225) was purchased from EMD Millipore (Billerica, MA, USA).

Cell culture and maintenance. The prostate cancer PC-3 and LNCaP cell lines were purchased from American Type Culture Collection (Manassas, VA, USA) and routinely maintained in DMEM supplemented with $10 \%$ FBS and $100 \mathrm{U} / \mathrm{ml}$ penicillin and $100 \mu \mathrm{g} / \mathrm{ml}$ streptomycin, at $37^{\circ} \mathrm{C}$ in a humidified chamber.

Isolation and maintenance of human peripheral blood mononuclear cells (PBMC). Human PBMC were isolated from the whole blood of adult healthy donors using the density gradient Ficoll-Hypaque (Histopaque 1077, Sigma Aldrich; Merck KGaA) method. Whole blood collected from the donor was carefully mixed with equal volume of Ficoll-Hypaque and centrifuged at $400 \mathrm{x}$ g for $30 \mathrm{~min}$ at room temperature. The PBMC were collected from the plasma/Ficoll-Hypaque interphase, washed in PBS (twice for $30 \mathrm{~min}$ ) and resuspended in RPMI-1640 complete medium (Invitrogen; Thermo Fisher Scientific, Inc.) supplemented with $10 \%$ FBS. The present study was approved by the Ethical Committee Board of Linyi People's Hospital (Linyi, China). Donors provided written informed consent to the inclusion of their samples in the present study.

Cell viability assay (MTT assay). Cultured prostate cancer cells $\left(1 \times 10^{4}\right.$ cells $\left./ \mathrm{ml}\right)$ were treated with different concentrations of tangeretin $(0,25,50 \mu \mathrm{M})$ for 24,48 and $72 \mathrm{~h}$. Following treatment, MTT solution $(0.5 \mathrm{mg} / \mathrm{ml}$; Thermo Fisher Scientific, Inc.) was added to each well followed by $100 \mu \mathrm{l}$ of isopropanol (10\%)/PBS and the resultant purple-blue formazan complex was measured using a Varian Cary 50MPR microplate reader
(Akribis Scientific, Knutsford, UK) at an absorbance $570 \mathrm{~nm}$, as described previously (26).

Apoptosis assay. Induction of apoptosis by tangeretin in prostate cancer cells was determined by ELISA-based apoptosis detection kit (EMD Millipore) following previously described protocol (27). Cultured prostate cancer cells $\left(1 \times 10^{4}\right.$ cells $\left./ \mathrm{ml}\right)$ were treated with different concentrations of tangeretin $(0,50$ and $75 \mu \mathrm{M}$ ) for $72 \mathrm{~h}$, and apoptosis was determined according to the manufacturer's protocol. Results were indicative to the absorbance recorded at $405 \mathrm{~nm}$ using s Varian Cary 50MPR microplate reader.

Hoechst 33258 staining of the apoptotic nuclei. Cultured prostate cancer cells $\left(1 \times 10^{4}\right.$ cells $\left./ \mathrm{ml}\right)$ were treated with tangeretin $(0,50$ and $75 \mu \mathrm{M})$ for $72 \mathrm{~h}$ and following treatment, cells were fixed in $4 \%$ paraformaldehyde and stained with $20 \mu \mathrm{M}$ Hoechst 33258 for $20 \mathrm{~min}$. Cells were then observed and images (NIS imaging system software 4.5 ver) were captured at a magnification of x100 using an inverted fluorescence microscope.

Anchorage-dependent and-independent colony formation assay. The anchorage-dependent growth properties of PC-3 cells were evaluated by their ability to form viable colonies. Cultured PC-3 cells $\left(1 \times 10^{4}\right.$ cells $\left./ \mathrm{ml}\right)$ were treated with tangeretin $(0,50$ and $75 \mu \mathrm{M})$ for $72 \mathrm{~h}$. Following treatment, single cell suspensions were prepared from the control and treated groups, and cells were finally seeded at a density of $\sim 500$ cells $/ \mathrm{ml}$. Cells were cultured for 7 days and the viable colonies were stained for $10 \mathrm{~h}$ with $0.5 \mathrm{mg} / \mathrm{ml}$ crystal violet at $37^{\circ} \mathrm{C}$. Colony forming efficiency (CFE) was determined by re-suspending the crystal violet stained cells in $10 \%$ acetic acid solution and measuring the absorbance at $600 \mathrm{~nm}$.

Anchorage-independent growth was assessed by seeding the control and tangeretin-treated cells on soft agar (0.4\% top layer, $0.8 \%$ bottom layer). Cultured PC-3 cells $\left(1 \times 10^{4}\right.$ cells $\left./ \mathrm{ml}\right)$ were treated with tangeretin $(0,50$ and $75 \mu \mathrm{M})$ for $72 \mathrm{~h}$. Following treatment, single cell suspension was prepared from the control and treated groups, and finally seeded on soft agar-coated 96-well plates, following previously described protocol (28). The colonies were counted after 14 days using an inverted microscope (magnification, x200).

Wound healing assay. The migratory activities of PC-3 cells were determined by a wound-healing assay. Cultured PC-3 cells were grown to $\sim 80 \%$ confluency, and a wound was created with a sterile plastic pipette tip. Cells were then allowed to migrate for $48 \mathrm{~h}$ in the absence and presence of $75 \mu \mathrm{M}$ tangeretin, and images were captured using a phase contrast microscope (magnification, x100).

Determination of invasion by Boyden Chamber Assay. The invasive properties of PC-3 cells were determined by a Boyden chamber assay, using Matrigel ${ }^{\circledR}$-coated invasion chambers (BD Biosciences, Franklin Lakes, NJ, USA) (29). PC-3 cells were treated with $75 \mu \mathrm{M}$ tangeretin for $72 \mathrm{~h}$, and $1 \times 10^{3}$ cells were loaded in the upper part of the Boyden chamber. Cells that invaded into the lower surface of the membrane were stained with $0.5 \mathrm{mg} / \mathrm{ml}$ crystal violet for $6 \mathrm{~h}$ and the resultant crystal violet complex was then dissolved in $10 \%$ acetic acid. 
Finally, the absorbance was measured at $600 \mathrm{~nm}$, using the Varian Cary 50MPR microplate reader to determine the extent of invasion.

Quantitative reverse transcription polymerase chain reaction $(R T-q P C R)$. Total RNA from the control and tangeretin-treated PC-3 cells were isolated using TRIzol reagent (Invitrogen; Thermo Fisher Scientific, Inc.) according to the manufacturers' protocol. Reverse transcription of the extracted RNA to corresponding complementary DNA was performed using a commercially available kit (Takara Bio, Inc., Otsu, Japan). RT-qPCR was performed with QuantiTech SYBR ${ }^{\circledR}$ Green PCR Kit (Qiagen GmbH, Hilden, Germany) according to the manufacturer's protocol, as previously described (30). A list of the used primers for all genes are in Table I. The reaction parameters selected were: $95^{\circ} \mathrm{C}$ for $5 \mathrm{~min}$, and the 40 cycles of $95^{\circ} \mathrm{C}$ for $10 \mathrm{sec}$ and $60^{\circ} \mathrm{C}$ for $30 \mathrm{sec}$. The $G A P D H$ gene was used as the endogenous control. Relative quantification values for each sample were determined using the $2^{-(\Delta \Delta \mathrm{Cq})}$ method (30).

Western blot analysis. Cultured PC-3 cells were treated with tangeretin $(0,50$ and $75 \mu \mathrm{M})$ for $72 \mathrm{~h}$, washed with PBS and incubated with RIPA lysis buffer (Sigma-Aldrich; Merck KGaA) for $2 \mathrm{~h}$ at $37^{\circ} \mathrm{C}$. The resultant cell lysates were centrifuged at $3,000 \mathrm{x} \mathrm{g}$ for $10 \mathrm{~min}$ at $37^{\circ} \mathrm{C}$ and total cellular protein was calculated using a BCA Protein Assay Reagent kit (BioVision, Inc., Milpitas, CA, USA). Equal quantities of protein $(50 \mu \mathrm{g} /$ lane) was separated by $10 \%$ SDS-PAGE, and then electrotransferred onto a nitrocellulose membrane by a semi-dry blotting system (GE Healthcare, Little Chalfont, UK). The membrane was blocked with Tris-buffered saline (TBS) containing Tween-20 and 5\% skimmed milk and probed with the following primary antibodies: Rabbit polyclonal anti-B-cell lymphoma 2 (Bcl-2)-associated X protein (Bax) (cat. no., sc493; 1:1,200) antibody, mouse monoclonal anti- Bcl-2 antibody (cat.no., sc-7382; 1:1,000) (Santa Cruz Biotechnology, Inc., Dallas, TX, USA) and rabbit polyclonal anti-cleaved caspase-3, rabbit monoclonal cleaved anti-caspase-9, rabbit monoclonal anti-phosphorylated (p)-protein kinase B (pAkt) (cat. no., 4060; 1:1,000), rabbit monoclonal anti-Akt (cat. no., 4691; 1:800), rabbit monoclonal anti-p-mammalian target of rapamycin (pmTOR) (cat. no., 5536; 1:1,000) and rabbit monoclonal anti-mTOR (cat. no., 2983; 1:1,200) as well as mouse monoclonal anti-rat $\beta$-actin antibody (cat. no., 5723; 1:1,500) (Cell Signaling Technology, Inc., Danvers, MA, USA) at $4^{\circ} \mathrm{C}$ for $10 \mathrm{~h}$. Subsequently, samples were incubated with goat anti-rabbit (cat. no., sc-2979; dilution, 1:10,000) and anti-mouse (cat. no., sc-358914; dilution, 1:10,000) secondary antibodies conjugated to horseradish peroxidase-conjugated (Santa Cruz Biotechnology, Inc.) secondary antibody in TBS at room temperature for $1 \mathrm{~h}$ and washed with TBS. The bound antibodies were visualized using an Enhanced Chemiluminescence system (Bio-Rad Laboratories, Inc., Hercules, CA, USA) and densitometry analysis was then performed (ChemiDoc-17001401; Image Lab-5.2.1; Bio-Rad Laboratories, Inc.).

Statistical analysis. All data are expressed as the mean \pm standard deviation. Statistically significant differences between
Table I. List of genes, with their primer sequences, used for quantitative reverse transcription polymerase chain reaction.

\begin{tabular}{ll}
\hline Gene & \multicolumn{1}{c}{ Primer sequence (5'-3') } \\
\hline $\begin{array}{l}\text { Vimentin } \\
\text { Forward } \\
\text { Reverse }\end{array}$ & AACTTAGGGGCGCTCTTGTC \\
CD44 & CCTGCTGTCCCGCCG \\
Forward & CCCAGATGGAGAAAGCTCTG \\
Reverse & GTTGTTTGCTGCACAGATGG \\
N-cadherin & \\
Forward & CCTTTCACTGCGGATACGTG \\
Reverse & GATCCAGGGGCTTTGTCACC \\
E-cadherin & \\
Forward & TGAGTGTCCCCCGGTATCTT \\
Reverse & GAATCATAAGGCGGGGCTGT \\
Cytokeratin & \\
Forward & CGGGGCCTCACTCTGCGATATAA \\
Reverse & GCGAGTGGTGAAGCTCATGC \\
\hline
\end{tabular}

E, epithelial; N, neural; CD, cluster of differentiation.

groups were determined by using the paired Student's two-tailed t-test. $\mathrm{P}<0.05$ was considered to indicate a statistically significant difference.

\section{Results}

Tangeretin induces loss of cell viability in prostate cancer cells, with negligible toxicity towards normal cells. The effect of tangeretin treatment on the viability of androgen-insensitive PC-3 and androgen-sensitive LNCaP cells was evaluated by MTT assay. Tangeretin induces a significant reduction of cell viability in PC-3 cells in a time- and dose-dependent manner (Fig. 1B). The $\mathrm{IC}_{50}$ for PC-3 cells was obtained following $72 \mathrm{~h}$ of incubation at $75 \mu \mathrm{M}$ dose of tangeretin. The androgen-sensitive LNCaP cells were identified to exhibit a slightly higher sensitivity to tangeretin treatment, with the $\mathrm{IC}_{50}$ obtained around $65 \mu \mathrm{M}$ following $72 \mathrm{~h}$ of treatment (Fig. 1C).

To evaluate the toxicity of tangeretin on normal cells, the viability of human PBMC in the presence of tangeretin was determined. Following treatment for 72 h, it was observed that tangeretin exhibited negligible cytotoxicity on PBMC compared with the cancer cells, and in the presence of $100 \mu \mathrm{M}$ tangeretin, the cell viability was decreased by only $20 \%$ (Fig. 1D).

Tangeretin induces apoptosis in prostate cancer cells with the modulation of pro- and anti-apoptotic markers. To determine the mode of cell death induced by tangeretin, the apoptosis assay was performed with tangeretin-treated PC-3 and LNCaP cells. The induction of apoptosis was determined using the ssDNA Apoptosis ELISA kit. Tangeretin treatment resulted in a dose-dependent induction of apoptosis in PC-3 cells (Fig. 2A). At a $50 \mu \mathrm{M}$ dose of tangeretin, apoptosis was increased $\sim 3$-fold $(\mathrm{P}<0.05)$, while in the presence of $75 \mu \mathrm{M}$ tangeretin, apoptosis 
A<smiles>COc1ccc(-c2cc(=O)c3c(OC)c(OC)c(OC)c(OC)c3o2)cc1</smiles>

C

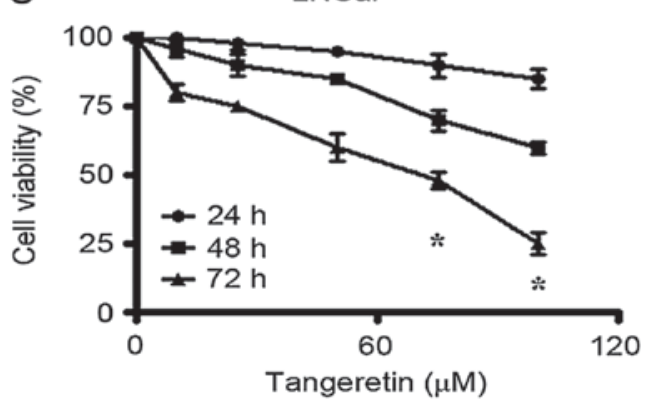

B

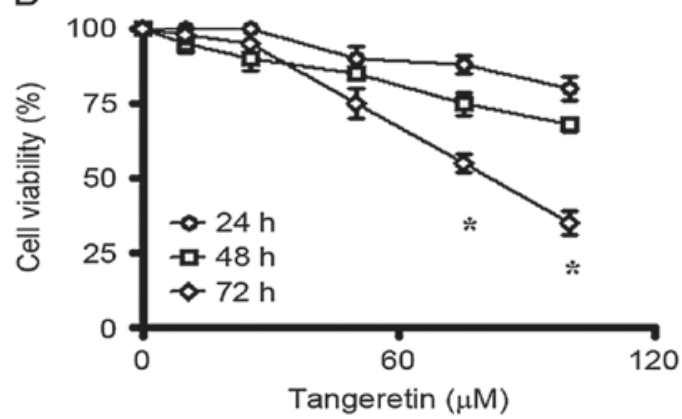

PBMC

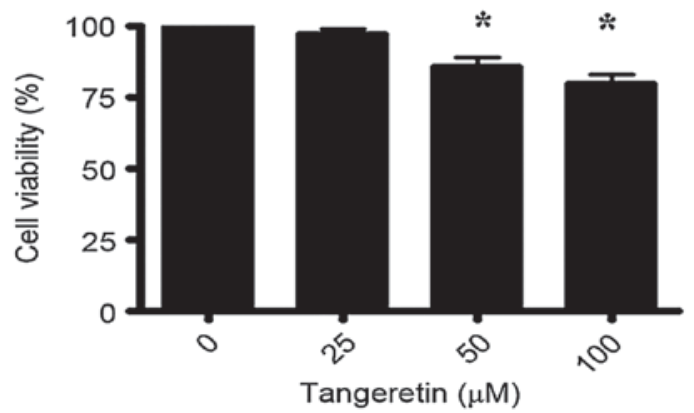

Figure 1. Reduction of cell viability by tangeretin. (A) Chemical structure of tangeretin. (B) Cultured PC-3 cells were grown in the presence or absence of different concentrations of tangeretin $(0-100 \mu \mathrm{M})$ for 24,48 and $72 \mathrm{~h}$, and cellular viability was determined by MTT assay. (C) Cultured LNCaP cells were grown in the presence or absence of different concentrations of tangeretin $(0-100 \mu \mathrm{M})$ for 24,48 and $72 \mathrm{~h}$, and cellular viability was determined by MTT assay. (D) Effect of tangeretin on PBMC viability. The results are expressed as mean \pm standard deviation of 3 independent experiments. ${ }^{*} \mathrm{P}<0.05$ vs. tangeretin-treated cells $(50$ and $100 \mu \mathrm{M})$. PBMC, peripheral blood mononuclear cells.

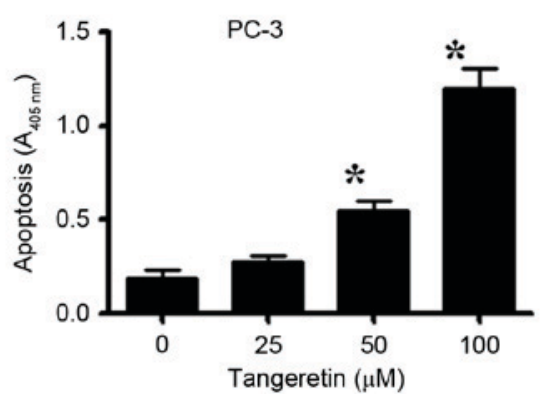

C

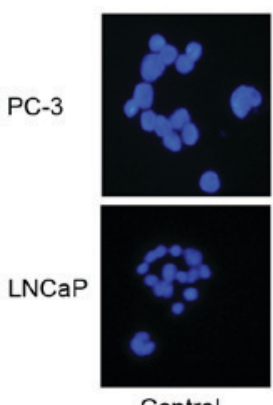

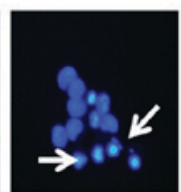

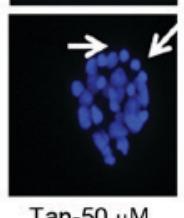

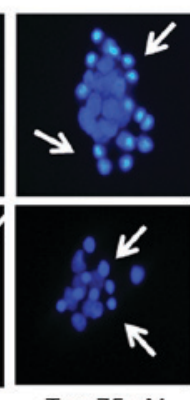

Tan- $75 \mu \mathrm{M}$

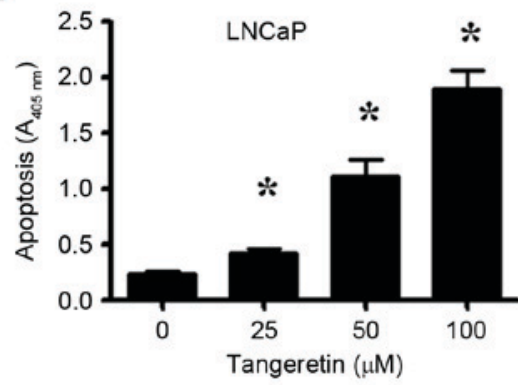

D

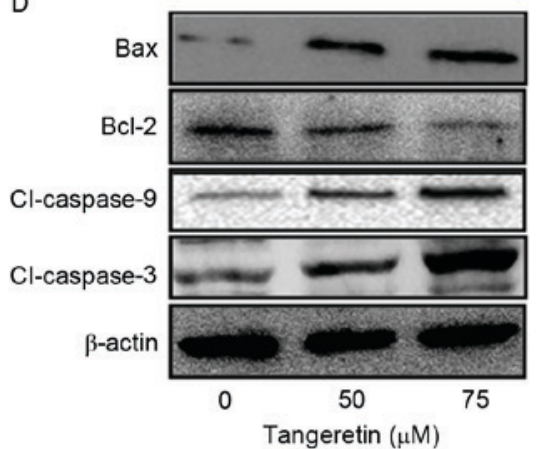

Figure 2. Induction of apoptosis and modulation of pro-and anti-apoptotic markers by tangeretin. (A) PC-3 cells were treated with tangeretin (0-75 $\mu \mathrm{M})$ for $72 \mathrm{~h}$, and apoptosis was determined using an apoptosis detection kit. (B) Induction of apoptosis in LNCaP cells by tangeretin. (C) Hoechst 33258 staining of the apoptotic nuclei of PC-3 and LNCaP cells treated with tangeretin $(0-75 \mu \mathrm{M})$. (D) Western blot analysis demonstrating the expression of Bax, Bcl-2, cleaved caspase- 3 and caspase-9 in control and tangeretin-treated PC-3 cells. Results are expressed as mean \pm standard deviation of three independent experiments. ${ }^{*} \mathrm{P}<0.05$ vs. tangeretin-treated cells (25, 50 and $\left.100 \mu \mathrm{M}\right)$. Tan, tangeretin; Bcl-2, B-cell lymphoma 2; Bax, Bcl-2-associated X protein; Cl, cleaved.

was increased 6.4-fold $(\mathrm{P}<0.05)$ compared with the control. Similarly, in LNCaP cells, treatment with $50 \mu \mathrm{M}$ tangeretin resulted in a 5.5-fold increase in apoptosis $(\mathrm{P}<0.05)$, while in the presence of $75 \mu \mathrm{M}$ tangeretin, apoptosis was increased 


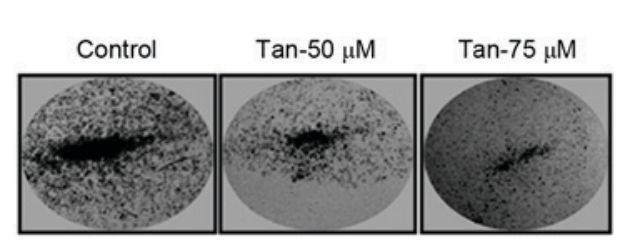

C

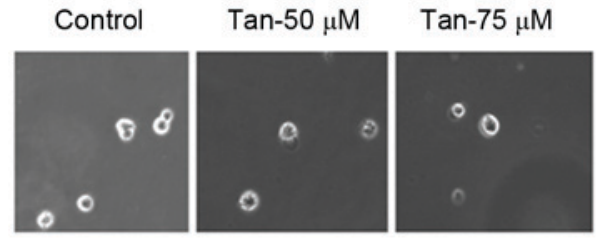

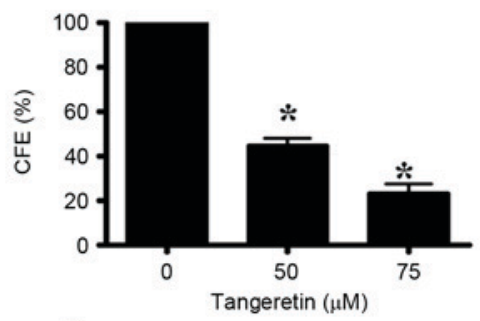

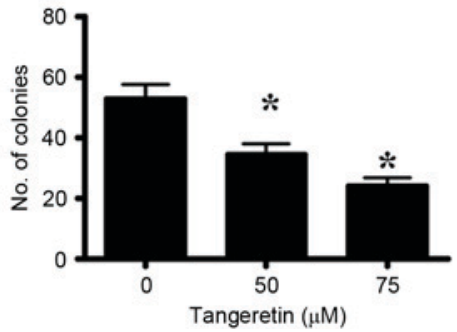

Figure 3. Inhibition of colony formation of PC-3 cells by tangeretin. (A) Colony formation of PC-3 cells in the absence and presence of tangeretin. (B) Proportion of CFE of control and tangeretin-treated PC-3 cells. (C) Anchorage-independent colony formation of control and tangeretin-treated PC-3 cells. (D) Average number of colonies formed by control and tangeretin-treated PC-3 cells under anchorage-independent growth conditions. Results are expressed as mean \pm standard deviation of 3 independent experiments. "P $<0.05$ vs. tangeretin-treated cells ( 50 and $100 \mu \mathrm{M})$. CFE, Colony forming efficiency.

by 7.5 -fold compared with the control $(\mathrm{P}<0.05$; Fig. 2B). Furthermore, in PC-3 and LNCaP cells, tangeretin treatment resulted in nuclear shrinkage, chromatin condensation and the formation of apoptotic bodies, as observed by Hoechst 33258 staining (Fig. 2C).

Subsequent to confirmation of the involvement of apoptosis in tangeretin-mediated cell death, the status of several anti- and pro-apoptotic markers was also investigated. The pro-apoptotic markers such as Bax, caspase-9 and caspase-3 were upregulated, and the anti-apoptotic Bcl-2 was downregulated in tangeretin-treated PC-3 cells (Fig. 2D).

Tangeretin inhibits colony-forming ability and anchorage-independent growth properties of $\mathrm{PC}-3$ cells. The colony-forming ability of PC-3 cells was markedly inhibited by tangeretin in a dose-dependent manner. PC-3 cells were treated with different doses of tangeretin $(0-75 \mu \mathrm{M})$ for $72 \mathrm{~h}$ and the residual cells were collected. Equal numbers of cells from control and treatment groups were then seeded to observe the colony formation and anchorage independent growth. The CFE was determined by crystal violet staining of the viable colonies. It was observed that tangeretin significantly inhibited the colony-forming ability of PC-3 cells in a dose-dependent manner $(\mathrm{P}<0.05$; Fig. $3 \mathrm{~A}$ and $\mathrm{B})$. In the presence of $50 \mu \mathrm{M}$ tangeretin, the CFE was reduced by $45 \%$, while at $75 \mu \mathrm{M}$ tangeretin the CFE is reduced by $23 \%$. Therefore, these results indicate that tangeretin inhibits the clonal growth in PC-3 cells.

The ability of the cancer cells to form colonies on soft agar due to their ability of anchorage-independent growth, is considered to be the hallmark of tumorigenesis. The untreated PC-3 cells, when seeded in the soft agar, formed several viable colonies. However, in the tangeretin-treated groups, the number of viable colonies was revealed to be significantly reduced $(\mathrm{P}<0.05$; Fig. 3C and D). Therefore, it may be concluded that tangeretin significantly inhibits the anchorage-independent growth potential of PC-3 cells.

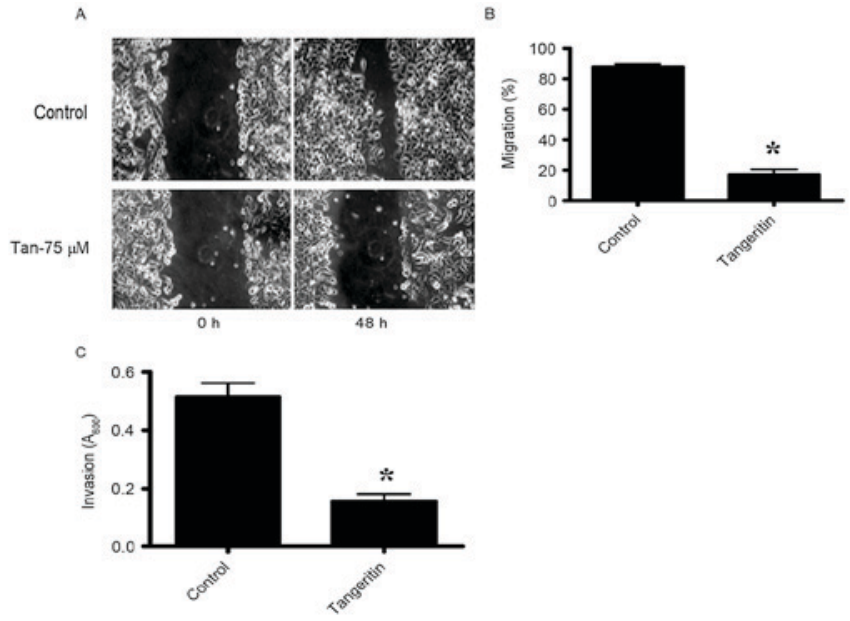

Figure 4. Inhibition of in vitro migration/invasion of PC-3 cells by tangeretin. (A) Wound healing assay of PC-3 cells treated with tangeretin. (B) Proportion of migration determined from the wound healing assay. (C) Invasion was determined by a Boyden Chamber assay. Results are expressed as mean \pm standard deviation of 3 independent experiments. ${ }^{*} \mathrm{P}<0.05$ vs. tangeretin-treated cells.

Tangeretin inhibits the motility of $\mathrm{PC}-3$ cells. The migratory activities of PC -3 cells were identified to be markedly inhibited by tangeretin as determined by the wound-healing assay (Fig. 4A and B). The control PC-3 cells covered $~ 80 \%$ of the wound following $48 \mathrm{~h}$ of incubation. However, in the presence of $75 \mu \mathrm{M}$ tangeretin, PC-3 cells completely failed to migrate. To additionally determine whether tangeretin may perturb the invasive properties of PC-3 cells, a matrigel invasion assay was performed using a Boyden Chamber assay. As hypothesized, the invasive properties of PC-3 cells were identified to be markedly inhibited in the presence of $75 \mu \mathrm{M}$ tangeretin (Fig. 4C). Therefore, the results clearly indicated that tangeretin reduced the migratory or invasive phenotype of PC-3 cells. 
A

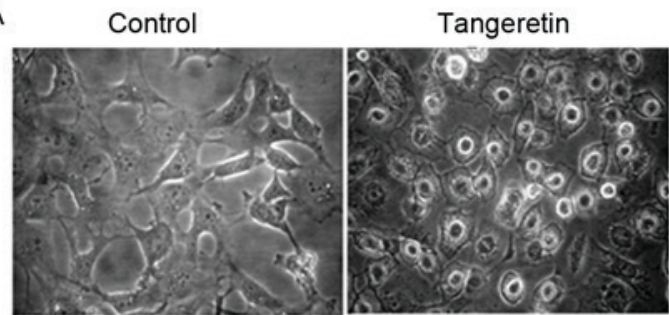

C

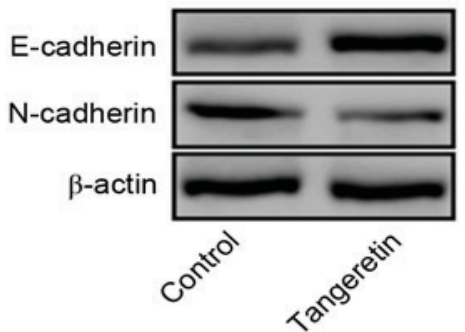

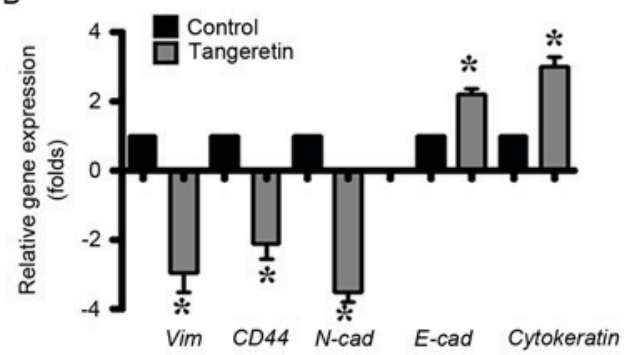

D

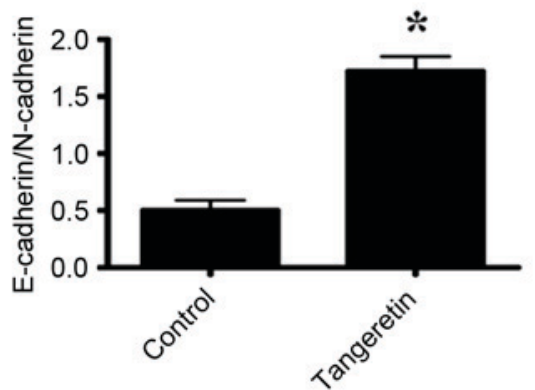

Figure 5. Reversal of EMT by tangeretin. (A) Phase contrast image of control and tangeretin-treated PC-3 cells. (B) Bar graph representing the expression levels of EMT-associated genes as obtained by quantitative reverse transcription polymerase chain reaction analysis. (C) Western blotting of N-cadherin and E-cadherin in control and tangeretin-treated PC-3 cells. (D) E-cadherin/N-cadherin ratio in control and tangeretin-treated PC-3 cells. Results are expressed as mean \pm standard deviation of 3 independent experiments. " $\mathrm{P}<0.05$ vs. tangeretin-treated cells $(100 \mu \mathrm{M})$. EMT, epithelial-mesenchymal transition; $\mathrm{N}$, neural; $\mathrm{E}$, epithelial; cad, cadherin; Vim, vimentin; CD44, cluster of differentiation 44.

A

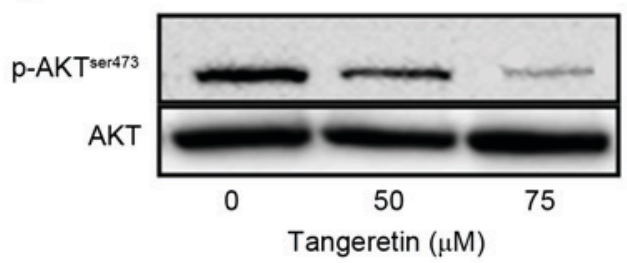

C

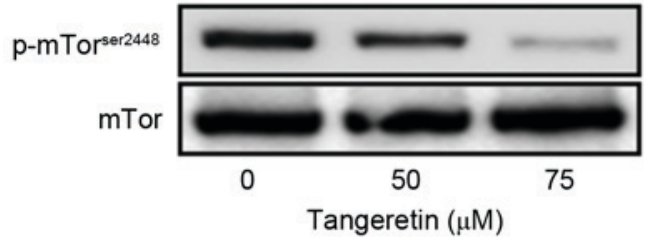

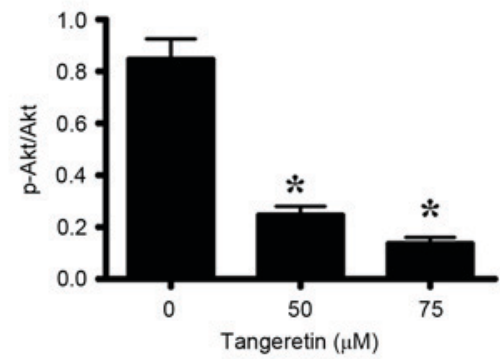

D

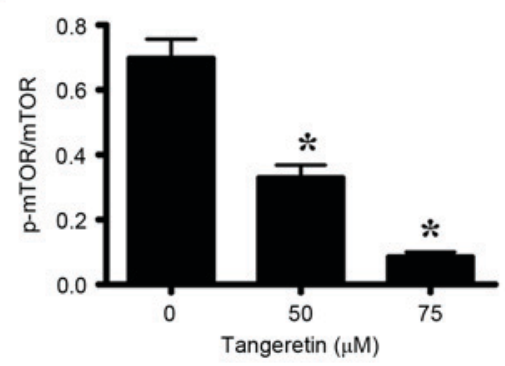

Figure 6. Effect of tangeretin on Akt/mTOR pathway. Cultured PC-3 cells were treated with different doses of tangeretin $(0-75 \mu \mathrm{M})$ for $72 \mathrm{~h}$. Western blot analyses for p-Akt (Ser 473), Akt, p-mTOR (Ser 2448) and mTOR were performed. (A) Western blotting for p-Akt (Ser 473) and Akt. (B) p-Akt /Akt ratio for control and tangeretin-treated PC-3 cells. (C) Western blotting for p-mTOR (Ser 2448) and mTOR. (D) p-mTOR/mTOR ratio for control and tangeretin-treated PC-3 cells. Results are expressed as mean \pm standard deviation of 3 independent experiments. ${ }^{*} \mathrm{P}<0.05$ vs. tangeretin-treated cells $(50$ and $100 \mu \mathrm{M})$. Akt, protein kinase B; mTOR, mammalian target of rapamycin; p, phosphorylated.

Tangeretin induces reprogramming of epithelial to mesenchymal transition in PC-3 cells. It was observed that subsequent to treatment with tangeretin, the morphology of PC-3 cells was significantly altered, and the treated cells exhibited an increased epithelial-like morphology compared with the mesenchymal morphology of the control cells (Fig. 5A). As EMT serves an important role in the progression and metastasis of prostate cancer, the gene expression of several EMT markers was determined by RT-qPCR analysis (Fig. 5B). It was observed that the expression levels of the 
genes encoding the mesenchymal proteins vimentin, cluster of differentiation (CD) 44 and N-cadherin were decreased by 3-, 2- and 3.5-fold, respectively whereas that of the epithelial markers such as E-cadherin and cytokeratin-19 were increased by 2.2- and 3-fold, respectively, in tangeretin-treated cells (as compared with the control; Fig. 5B). In addition, the western blot analysis revealed that the E-cadherin/N-cadherin ratio was significantly increased in tangeretin-treated cells compared with the control $(\mathrm{P}<0.05$; Fig. 5C and D).

Tangeretin targets Akt/mTOR pathway in PC-3 cells. Akt-signaling serves an important role in the maintenance of the tumor phenotype in prostate cancer $(31,32)$. Therefore, the present study investigated the phosphorylation of Akt, and its downstream modulator mTOR, in tangeretin-treated PC-3 cells. Tangeretin significantly decreased the phosphorylation levels of Akt in a dose-dependent manner ( $\mathrm{P}<0.05$; Fig. 6A and $\mathrm{B})$. In the presence of 50 and $75 \mu \mathrm{M}$ tangeretin, pAkt levels were reduced by 64 and $82 \%$, respectively when compared with the control (Fig. 6A and B). Similarly, the expression levels of p-mTOR were significantly reduced by 49 and $85 \%$, respectively $(\mathrm{P}<0.05$; Fig. 6C and D). These results suggested that tangeretin efficiently inhibited Akt signaling in PC-3 cells.

\section{Discussion}

A number of epidemiological studies have indicated that, instead of a particular specific carcinogen, several factors associated with lifestyle, dietary, and environmental factors may serve as the etiology of prostate cancer $(2,4-7)$. Due to the minimum toxicity towards normal cells, and selective cytotoxicity against cancer cells, naturally-occurring dietary flavonoids have gained importance as anticancer therapeutics (18-20). In the present study, the anticancer potential of tangeretin, a 4',5,6,7,8-pentamethoxyflavone, against prostate carcinoma was investigated. Although tangeretin has been suggested to be effective against several types of cancer (22-25), its role against prostate cancer has not been determined and requires additional investigation.

The present study observed that treatment of the prostate cancer PC-3 and LNCaP cell lines with tangeretin resulted in dose-and time-dependent loss of cell viability, with negligible cytotoxicity in PBMC. In addition, it was also observed that tangeretin induces caspase-3-mediated apoptosis in prostate cancer cells. The ability to form colonies by PC-3 cells under anchorage-dependent and -independent conditions was also inhibited by tangeretin in a dose-dependent manner. As hypothesized, it was also observed that tangeretin treatment also inhibited the motility of PC-3 cells, as revealed by the migration and invasion assays.

EMT is an important pathophysiological process which serves an important role in the metastasis of prostate cancer to distant organs, and also in the maintenance of stemness $(8,13,15,16)$. As tangeretin induces a marked alteration to the morphology of PC-3 cells, the statuses of EMT markers in tangeretin-treated PC-3 cells were investigated. The expression levels of the genes encoding the mesenchymal proteins vimentin, CD-44 and N-cadherin were significantly downregulated by tangeretin, whereas the epithelial markers such as E-cadherin and cytokeratin-19 were significantly upregulated.
Additionally, the E-cadherin/N-cadherin ratio was significantly upregulated by tangeretin treatment, indicating the reversal of EMT in tangeretin-treated PC-3 cells.

Akt, a serine/threonine protein kinase, is a key regulator of apoptosis, regulating the downstream signaling pathway of apoptosis, whereas mTOR acts as a downstream effector for Akt and regulates key processes such as cell growth and proliferation and cell cycle progression $(31,32)$. Deregulation of this pathway in prostate cancer is well documented, and it has been demonstrated that the phosphoinositide 3-kinase (PI3K)/Akt/mTOR pathway is deregulated in $42 \%$ of localized disease and $100 \%$ of advanced-stage carcinoma (33). Therefore, this signaling pathway may be a potential drug target in the treatment of prostate cancer. In the present study, it was observed that tangeretin treatment of PC-3 cells resulted in a marked reduction of $\mathrm{p}$-Akt levels, and also p-mTOR levels were also decreased. However, the total Akt or mTOR levels remained unaltered.

Therefore, the present study presented a novel therapeutic approach to prostate cancer. The dietary flavonoid tangeretin was identified to be effective against PC-3 cells. Reprogramming of the EMT process, via downregulation of $\mathrm{PI} 3 \mathrm{~K} / \mathrm{Akt} / \mathrm{mTOR}$ pathway serves as the primary mechanism of tangeretin-induced cytotoxicity in PC-3 cells.

\section{References}

1. Shelke AR and Mohile SG: Treating prostate cancer in elderly men: How does aging affect the outcome? Curr Treat Options Oncol 12: 263-275, 2011.

2. Crawford ED: Understanding the epidemiology, natural history, and key pathways involved in prostate cancer. Urology 73 (5 Suppl): S4-S10, 2009.

3. Bosland MC: The role of steroid hormones in prostate carcinogenesis. J Natl Cancer Inst Monogr: 39-66, 2000.

4. Crawford ED: Prostate cancer. Introduction. Urology 62 (6 Suppl 1): S1-S2, 2003

5. Grönberg H: Prostate cancer epidemiology. Lancet 361: 859-864, 2003.

6. Crawford ED: Epidemiology of prostate cancer. Urology 62 (6 Suppl 1): S3-S12, 2003.

7. Whittemore AS, Kolonel LN, Wu AH, John EM, Gallagher RP, Howe GR, Burch JD, Hankin J, Dreon DM, West DW, et al: Prostate cancer in relation to diet, physical activity, and body size in blacks, whites, and Asians in the United States and Canada. J Natl Cancer Inst 87: 652-661, 1995.

8. Gravdal K, Halvorsen OJ, Haukaas SA and Akslen LA: A switch from $\mathrm{E}$-cadherin to $\mathrm{N}$-cadherin expression indicates epithelial to mesenchymal transition and is of strong and independent importance for the progress of prostate cancer. Clin Cancer Res 13: 7003-7011, 2007.

9. Kalluri R and Weinberg RA: The basics of epithelial-mesenchymal transition. J Clin Invest 119: 1420-1428, 2009.

10. Tomita K, van Bokhoven A, van Leenders GJ, Ruijter ET, Jansen CF, Bussemakers MJ and Schalken JA: Cadherin switching in human prostate cancer progression. Cancer Res 60: 3650-3654, 2000.

11. Shiozawa Y, Pedersen EA, Havens AM, Jung Y, Mishra A, Joseph J, Kim JK, Patel LR, Ying C, Ziegler AM, et al: Human prostate cancer metastases target the hematopoietic stem cell niche to establish footholds in mouse bone marrow. J Clin Invest 121: 1298-1312, 2011.

12. Steeg PS: Cancer biology: Emissaries set up new sites. Nature 438: 750-751, 2005.

13. Alexander NR, Tran NL, Rekapally H, Summers CE, Glackin C and Heimark RL: N-cadherin gene expression in prostate carcinoma is modulated by integrin-dependent nuclear translocation of Twist1. Cancer Res 66: 3365-3369, 2006.

14. Collins AT, Berry PA, Hyde C, Stower MJ and Maitland NJ: Prospective identification of tumorigenic prostate cancer stem cells. Cancer Res 65: 10946-10951, 2005. 
15. Kong D, Banerjee S, Ahmad A, Li Y, Wang Z, Sethi S and Sarkar FH: Epithelial to mesenchymal transition is mechanistically linked with stem cell signatures in prostate cancer cells. PLoS One 5: e12445, 2010.

16. Maitland NJ and Collins A: A tumour stem cell hypothesis for the origins of prostate cancer. BJU Int 96: 1219-1223, 2005

17. Pavese JM and Bergan RC: Circulating tumor cells exhibit a biologically aggressive cancer phenotype accompanied by selective resistance to chemotherapy. Cancer Lett 352: 179-186, 2014

18. Sak K: Site-specific anticancer effects of dietary flavonoid quercetin. Nutr Cancer 66: 177-193, 2014.

19. Sak K: Cytotoxicity of dietary flavonoids on different human cancer types. Pharmacogn Rev 8: 122-146, 2014.

20. Gupta S, Afaq F and Mukhtar H: Selective growth-inhibitory, cell-cycle deregulatory and apoptotic response of tangeretin in normal versus human prostate carcinoma cells. Biochem Biophys Res Commun 287: 914-920, 2001.

21. Pan MH, Chen WJ, Lin-Shiau SY, Ho CT and Lin JK: Tangeretin induces cell-cycle G1 arrest through inhibiting cyclin-dependent kinases 2 and 4 activities as well as elevating Cdk inhibitors p21 and p27 in human colorectal carcinoma cells. Carcinogenesis 23: $1677-1684,2002$

22. Arafa el SA,Zhu Q, Barakat BM, Wani G, Zhao Q,El-Mahdy MA and Wani AA: Tangeretin sensitizes cisplatin-resistant human ovarian cancer cells through downregulation of phosphoinositide 3-kinase/Akt signaling pathway. Cancer Res 69: 8910-8917, 2009.

23. Dong Y, Cao A, Shi J, Yin P, Wang L, Ji G, Xie J and Wu D: Tangeretin, a citrus polymethoxyflavonoid, induces apoptosis of human gastric cancer AGS cells through extrinsic and intrinsic signaling pathways. Oncol Rep 31: 1788-1794, 2014.

24. Lakshmi A and Subramanian S: Chemotherapeutic effect of tangeretin, a polymethoxylated flavone studied in 7 12-dimethylbenz(a)anthracene induced mammary carcinoma in experimental rats. Biochimie 99: 96-109, 2014.

25. Periyasamy K, Baskaran K, Ilakkia A, Vanitha K, Selvaraj S and Sakthisekaran D: Antitumor efficacy of tangeretin by targeting the oxidative stress mediated on 7,12-dimethylbenz(a) anthracene-induced proliferative breast cancer in Sprague-Dawley rats. Cancer Chemother Pharmacol 75: 263-272, 2015.
26. Das A, Bhattacharya A, Chakrabarty S, Ganguli A and Chakrabarti G: Smokeless tobacco extract (STE)-induced toxicity in mammalian cells is mediated by the disruption of cellular microtubule network: A key mechanism of cytotoxicity. PLoS One 8: e68224, 2013.

27. Balint K, Xiao M, Pinnix CC, Soma A, Veres I, Juhasz I, Brown EJ, Capobianco AJ, Herlyn M and Liu ZJ: Activation of Notch1 signaling is required for beta-catenin-mediated human primary melanoma progression. J Clin Invest 115: 3166-3176, 2005.

28. Di Cello F, Flowers VL, Li H, Vecchio-Pagán B, Gordon B, Harbom K, Shin J, Beaty R, Wang W, Brayton C, et al: Cigarette smoke induces epithelial to mesenchymal transition and increases the metastatic ability of breast cancer cells. Mol Cancer 12: 90 2013.

29. Tanno B, Sesti F, Cesi V, Bossi G, Ferrari-Amorotti G, Bussolari R, Tirindelli D, Calabretta B and Raschellà G: Expression of Slug is regulated by c-Myb and is required for invasion and bone marrow homing of cancer cells of different origin. J Biol Chem 285: 29434-29445, 2010.

30. Livak KJ and Schmittgen TD: Analysis of relative gene expression data using real-time quantitative PCR and the 2(-Delta Delta C(T)) method. Methods 25: 402-408, 2001.

31. Chang L, Graham PH, Hao J, Ni J, Bucci J, Cozzi PJ, Kearsley JH and Li Y: Acquisition of epithelial-mesenchymal transition and cancer stem cell phenotypes is associated with activation of the $\mathrm{PI} 3 \mathrm{~K} / \mathrm{Akt} / \mathrm{mTOR}$ pathway in prostate cancer radioresistance. Cell Death Dis 4: e875, 2013.

32. Ni J, Cozzi P, Hao J, Beretov J, Chang L, Duan W, Shigdar S, Delprado W, Graham P, Bucci J, et al: Epithelial cell adhesion molecule (EpCAM) is associated with prostate cancer metastasis and chemo/radioresistance via the PI3K/Akt/mTOR signaling pathway. Int J Biochem Cell Biol 45: 2736-2748, 2013.

33. Taylor BS, Schultz N, Hieronymus H, Gopalan A, Xiao Y, Carver BS, Arora VK, Kaushik P, Cerami E, Reva B, et al: Integrative genomic profiling of human prostate cancer. Cancer Cell 18: 11-22, 2010. 